\title{
Raman Spectroscopy of Hemoglobin and Dielectrophoresis of Erythrocytes in the Diagnosis of the Resistant Arterial Hypertension
}

\author{
Margarita V. Kruchinina ${ }^{1}$, Andrey A. Gromov ${ }^{1}$, Vladimir N. Kruchinin ${ }^{2 *}$, Vladimir A. Volodin ${ }^{2}$, and \\ Vladimir M. Generalov ${ }^{3}$ \\ ${ }^{1}$ Research Institute of Internal and Preventive Medicine - Branch of the Institute of Cytology and Genetics, Siberian \\ Branch of the Russian Academy of Sciences, 175/1 Bogatkova Str., Novosibirsk 630089, Russia \\ ${ }^{2}$ Rzhanov Institute of Semiconductor Physics, SB RAS, 13 Lavrentieva Ave., Novosibirsk 630090, Russia \\ ${ }^{3}$ Federal Budgetary Research Institution "State Research Center of Virology and Biotechnology "Vector", Federal \\ Service for Surveillance on Consumer Rights Protection and Human Well-being, Novosibirsk Region, Koltsovo 630559, \\ Russia
}

*e-mail: vladd.kruch@yandex.ru

\begin{abstract}
The research aim is to study the associations of changes in the content of hemoglobin complexes by the Raman spectroscopy with electrical and viscoelastic parameters of erythrocytes (using the dielectrophoresis method) among patients with arterial hypertension $(\mathrm{AH})$ (including resistant $\mathrm{AH}$ ), to evaluate the possibility of using these parameters for diagnostic purposes. Fifty males ( $54 \pm 6$ years) with stage 2 of AH have been examined, 24 of them have showed resistant $\mathrm{AH}$. We have determined a significant decrease in the level of hemoglobin-ligand complexes, Hb-NO (II) complexes in patients with resistant AH compared to those among patients with controlled $\mathrm{AH}$ and among healthy patients $(p<0.001-0.05)$. We have found correlations between intensities of the most important signals of hemoglobin Raman spectra $(1325,1350,1550,1580$, $1660,1668 \mathrm{~cm}^{-1}$ ) and electric and viscoelastic parameters of erythrocytes (amplitude of erythrocytes deformation, summarized indicators of viscosity and rigidity, the magnitude of the dipole moment, polarizability at the frequency $106 \mathrm{~Hz}$, electrical conductivity, index of destruction), the intensity of which had been the biggest one for resistant AH. It has been shown that the combined use of two methods (Raman spectroscopy of hemoglobin and electrical and the studies of erythrocytes by the dielectrophoresis method) allowed to increase the diagnostic accuracy to detect the resistant arterial hypertension up to $88 \%$, sensitivity up to $84.6 \%$, specificity up to $91.7 \%$ compared to the data of the combined clinical and instrumental methods of research. The capability of this combination approach exceeds the capabilities of the methods separately. (C) 2020 Journal of Biomedical Photonics \& Engineering.
\end{abstract}

Keywords: resistant arterial hypertension; diagnostics; Raman spectroscopy; dielectrophoresis; erythrocytes; hemoglobin.

Paper \#3352 received 22 Feb 2020; revised manuscript received 8 Mar 2020; accepted for publication 27 Mar 2020; published online 21 Jun 2020. doi: 10.18287/JBPE20.06.020302.

\section{Introduction}

Diagnostic issues and therapeutic tactics for patients with resistant arterial hypertension (RAH) are very relevant due to its high prevalence (it ranges 3 to $24 \%$ among patients receiving antihypertensive therapy $[1$, 2]), an ambiguity of the mechanisms of refractoriness appearance [3], the role of various factors, such as 
endothelium [4], regulatory cytokines, immunological components, blood cells that affect the development of the RAH.

One of the possible pathogenetic factors influencing the development of RAH is a violation of the bioavailability of nitrogen oxide (NO) produced by erythrocytes [5]. There are three main sources of NO in the body, two of which are associated with erythrocytes: there are S-Nitrosothiols of hemoglobin and NO produced by hemoglobin nitrite reductase [6]. The role of erythrocytes as a participant of the vasoregulation is connected with both a direct "liberation" of NO and stimulation of nitrogen oxide liberation by the endothelium through ATP synthesis by involving erythrocytes. The ATP release from erythrocytes occurs in response to their mechanical deformation: declining plasticity of erythrocytes leads to a decrease in ATP levels, and, consequently, to a decrease in the NO synthesis. The aspect of the interplay between erythrocytes and NO for patients with RAH is very promising in terms of existing possibilities to intervene in NO metabolism [7-9].

Modern approaches of the diagnosis of RAH imply the use of a whole set of studies to exclude a pseudoresistant $\mathrm{AH}$, as well as the factors contributing to resistance of antihypertensive therapy, secondary $\mathrm{AH}$, associated clinical conditions (metabolic syndrome, obesity, smoking, alcohol), genetic characteristics [2, 10]. However, if the resistance persists after the exclusion of the factors described above, possible pathogenetic disorders come to the fore, including the effect of nitrogen oxide levels [11].

Previous pilot studies to identify pathogenetic features of the RAH have proved the promising approach, associated with the assessment of the NOhemoglobin complexes level for the diagnosis of this pathology [12-14]. At the same time, we have received information about a close association of electrical and viscoelastic parameters of erythrocytes with the development of resistant hypertension [15].

The hypothesis of the present study was the assumption of a possible association of altered levels of hemoglobin complexes with electrical and viscoelastic parameters of erythrocytes that can be used for diagnostic purposes for patients with $\mathrm{AH}$.

This fact has determined our choice of research methods. To determine the content of the NOhemoglobin complexes of erythrocytes for patients with $\mathrm{AH}$, a modern physical and chemical research method of biological media, namely the coherent Raman scattering spectroscopy (Raman spectroscopy), was used. This method has all the advantages of optical methods that are important for the study of biological objects (high sensitivity, non-destructive nature of impact on biological objects, lack of complex sample preparation) and it has been successfully used for various studies $[16,17]$.

The study of electrical and viscoelastic parameters of erythrocytes has been performed by the dielectrophoresis method in an non-uniform alternating electric field (NUAEF), which demonstrated high efficiency in the diagnosis of diffuse liver disease, cardiovascular diseases, and cancer processes, being of non-invasive, informative, and low-cost nature [18-23].

Research aim is to identify the dependence of the content of hemoglobin complexes (Raman spectroscopy) on the electrical and viscoelastic parameters of the erythrocytes (dielectrophoresis) for the patients with $\mathrm{AH}$, including the resistant one, and to evaluate the possibility of applying the results for diagnostic purposes.

\section{Materials and methods}

Fifty males ( $54 \pm 6$ years) with $2 \mathrm{AH}$ stage have been examined, 24 of them showed RAH [10]. We have analyzed patients with controlled hypertension (26 persons - group 1) and resistant hypertension (24 persons - group 2) separately. The comparison group consisted of 25 males of comparable age ( $52 \pm 7$ years) without hypertension and any other manifesting pathology of internal organs. Criteria for inclusion in the study were as follows: 1) males 40-60 years old with or without stage II of hypertension; 2) signing an informed consent to participate in the study.

The survey was performed with the approval of the Biomedical Ethics Committee of the Research Institute of Internal and Preventive Medicine (session of 15.01.2017).

The patients have undergone a comprehensive clinical, instrumental and laboratory examination, including electrocardiography, heart ultrasound, computed tomography, and electroencephalography.

According to the office measurement, the average blood pressure (BP) of the patients with RAH was $174 / 100 \pm 13 / 9 \mathrm{~mm} \mathrm{Hg}$; the Apnea-Hypopnea Index (AHI) $-63.8 \pm 3.6 ;$ BMI $-37.5 \pm 7.2 \mathrm{~kg} / \mathrm{m}^{2}$. All patients with RAH received multicomponent antihypertensive therapy, including angiotensinconverting enzyme inhibitors, aldosterone receptor antagonists, diuretics, beta-adrenergic blocking agents, calcium antagonists, and centrally acting antihypertensive drugs in maximum or maximum tolerated doses. Patients with RAH had the higher levels of clinically measured systolic and diastolic BP, AHI, longer duration of $\mathrm{AH}$ as compared to patients with controlled AH. $(12.9 \pm 4.8$ years vs $5.8 \pm 2.5$ years, $\mathrm{p}<0.01)(\mathrm{BP}-141.2 / 92.4 \pm 7.1 / 4.7 \mathrm{~mm} \mathrm{Hg}$; AHI $28.5 \pm 4.2 \mathrm{p}<0.01-0.05$ in patients with controlled BP, respectively).

The risk stratification of patients with hypertension is presented in Table 1. It shows that in a group of patients with RAH there are no patients with low additional risk, more often there are a high additional risk $(\mathrm{p}<0.01)$. 
Table 1 Risk stratification for patients with AH.

\begin{tabular}{ccc}
$\begin{array}{c}\text { Additional } \\
\text { risk }\end{array}$ & $\begin{array}{c}\mathbf{1}^{\text {st }} \text { group } \\
\text { (controlled AH) } \\
\mathbf{n}=\mathbf{2 6}\end{array}$ & $\begin{array}{c}\mathbf{2}^{\text {nd }} \text { group } \\
\text { (RAH) } \\
\mathbf{n}=\mathbf{2 4}\end{array}$ \\
\hline Low, n & 2 (no RF) & 0 \\
\hline Average, n & $16(1$ to 2 RFs $)$ & $5(1 \text { to } 2 \text { RFs })^{*}$ \\
\hline High, n & $\begin{array}{c}8 \text { (3 or more RFs, } \\
\text { TODs, MSs or } \\
\text { DMs })\end{array}$ & $\begin{array}{c}19(3 \text { or more } \\
\text { RFs, TODs, } \\
\text { MSs or DMs })^{*}\end{array}$
\end{tabular}

RF - risk factors, TOD - target organ damage, MS - metabolic syndrome, DM - diabetes mellitus;

* Statistically significant result between groups is $\mathrm{p}<0.01$.

Blood samples were obtained on an empty stomach from the ulnar vein using standard single-use sterile vacuum tubes with anticoagulant (citrate buffer of $3.7 \%$ in a ratio of 9:1). In groups of patients with $\mathrm{AH}$, as well as among males of the comparison group, the levels of hemoglobin complexes (deoxyhemoglobin (d-Hb), oxyhemoglobin (ox-Hb), hemoglobin complexes with nitrogen oxide (Hb-NO (I, II)) in its aqueous solutions were studied by Raman spectroscopy using a T64000 spectrometer (Horiba Jobin Yvon) with a triple monochromator. Preparation of hemoglobin solutions, conditions and sequence of measurements are described in Ref. [14].

The study of electrical and viscoelastic parameters of erythrocytes was performed by the dielectrophoresis method in an NUAEF using an automated specialized installation [19]. We evaluated the electrical conductivity of membranes, indices of aggregation and destruction of erythrocytes, the capacity of the cell membranes, the velocity of erythrocytes to the electrodes, the position of the crossover frequency, the amplitude of deformation of erythrocytes, polarizability of cells, summarized indices of viscosity and rigidity, the magnitude of induced dipole moment. The original CELLFIND software package was used for computer data processing. The error of the method assay reproducibility is equal to $7-12 \%$.

Statistical data processing was performed using the software SPSS ver. 17. The distribution of quantitative characteristics was determined by the KolmogorovSmirnov test. In the case of a normal distribution, the average value $(\mathrm{M})$ and the standard error of the mean (m) were calculated. The significance of the difference values was assessed by the Student's and Pearson's criteria (in a normal distribution), and nonparametric tests (Mann-Whitney U-test, Kolmogorov-Smirnov test) were used in cases of deviation from the normal distribution. The criterion $\chi^{2}$ was used for evaluating qualitative features. The relationships between features were evaluated using the partial correlation analysis. In all statistical analysis procedures, the critical significance level of the null hypothesis (p) was assumed to be equal to 0.05 . To assess the significance of the parameters of Raman spectroscopy and dielectrophoresis in terms of differential diagnosis of controlled and resistant hypertension, ROC analysis was used with the construction of characteristic curves (ROC curves).

\section{Results and discussion}

The Fig. 1 shows a typical spectrum of an aqueous hemoglobin solution obtained using the Raman spectroscopy. It allows one to evaluate changes in porphyrin conformation and levels of hemoglobin complexes (d-Hb, ox-Hb, and Hb-NO) [24]. The literature suggests that the ratio of Raman spectrum peaks $\mathrm{I}_{1355} / \mathrm{I}_{1564}$ indicates the ability of deoxyhemoglobin (d-Hb) to bind $\mathrm{O}_{2}$ and $\mathrm{NO}$; the complex with nitrogen oxide without breaking the connection between the protein and hemoporphyrin was estimated by the ratio of peaks $\mathrm{I}_{1626} / \mathrm{I}_{1580}$. The $\mathrm{Hb}$ complex with nitrogen oxide should regulate the ability of $\mathrm{Hb}$ to release $\mathrm{O}_{2}\left(\mathrm{I}_{1668} / \mathrm{I}_{1580}\right)$ when the proteinhemoporphyrin bond is broken. The peaks I, III correspond to the vibrational frequencies of deoxyhemoglobin molecules; peaks II, IV - of oxyhemoglobin molecules; peaks V, VI - comply with the vibrational frequencies of $\mathrm{NO}$ molecules associated with hemoglobin; the ratio (II/III) / (II/IV) reflects the affinity of hemoglobin to $\mathrm{O}_{2}$.

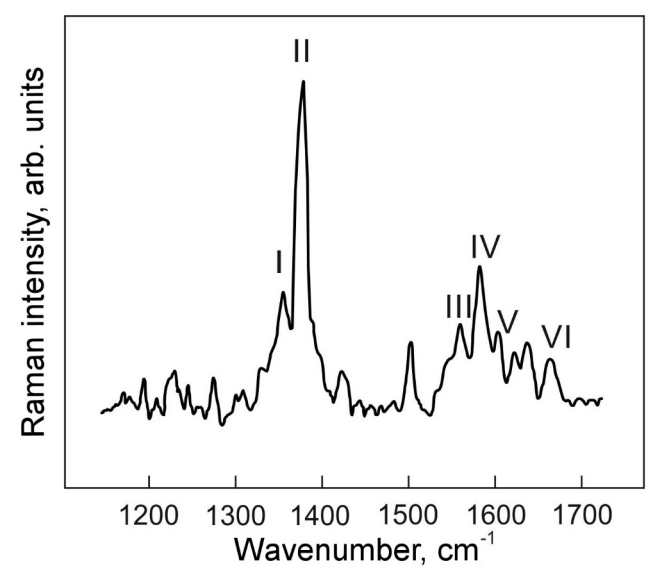

Fig. 1 A typical Raman spectrum of an aqueous hemoglobin solution. I, III - vibrational frequencies of deoxyhemoglobin molecules; II, IV - oxyhemoglobin molecules; V, VI - vibrational frequencies of NO molecules associated with hemoglobin; the ratio (II/III) / (II/IV) reflects the affinity of hemoglobin to $\mathrm{O}_{2}$ [24].

The hemoglobin complex with nitrogen oxide ( $\mathrm{Hb}-\mathrm{NO})$ regulates the ability of hemoglobin to release the oxygen when the bond between protein and hemoporphyrin was broken, that is measured by the ratio of Raman peaks $\mathrm{I}_{1680} / \mathrm{I}_{1580}$. We determined a 
significant decrease in the level of hemoglobin-ligand complexes, Hb-NO (II) complexes in patients with RAH compared to those among patients with controlled $\mathrm{AH}$ and among healthy patients $(\mathrm{p}<0.001-0.05)$, that probably reflects the reduced reserves of erythrocytic $\mathrm{NO}$ and a decrease in $\mathrm{O}_{2}$ release (Fig. 2). The ratio of signals $\mathrm{I}_{1680} / \mathrm{I}_{1580}$ in cases of resistant hypertension was the lowest in comparison with that in controlled hypertension and in the comparison group $(0.36 \pm 0.07$ vs $0.45 \pm 0.08$ in controlled hypertension, $\mathrm{p}<0.01^{-}$and $0.56 \pm 0.09$ under control, $\mathrm{p}<0.001$ ), reflecting a decrease in the ability of hemoglobin to give oxygen in RAH. Rodnenkov O. V. et al. [24] have observed a decrease in the level of $\mathrm{Hb}-\mathrm{NO}$ complexes in cases of coronary heart disease (CHD), hypertension, and circulatory insufficiency. The researchers had explained achieved result by increasing hypoxia in these pathologies; on the contrary, in cases of mountain sickness (hypoxia), an increase in the content of ox-Hb and $\mathrm{Hb}-\mathrm{NO}$ (II) complexes was observed that increases the exchange of $\mathrm{O}_{2}$ and probably has a compensatory character.

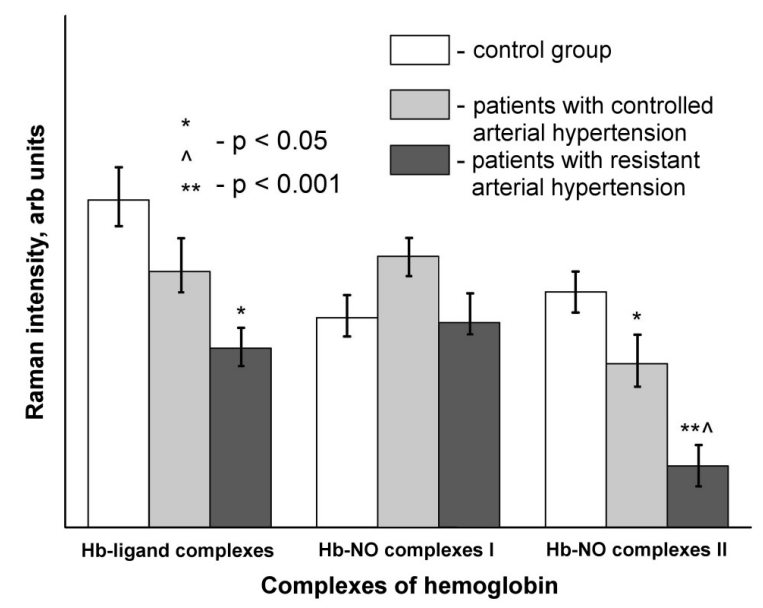

Fig. 2 Hemoglobin complexes levels according to the Raman spectroscopy among patients with RAH, controlled AH, and individuals in the comparison group. Statistically significant results: * - control group: $* \mathrm{p}<0.05, * * \mathrm{p}<0.001 ; \wedge$ patients with controlled AH: $\mathrm{p}<0.05$.

An insufficiency of the NO production system leading to endothelial dysfunction is to be considered as one of the renal mechanisms of RAH development. During the experiment, it was found that NO-synthase inhibitors were caused systemic and glomerular hypertension, glomerular ischemia, tubulointerstitial injury, and proteinuria. We obtained evidence for the relationship between the decrease in total NO production and renal damage for patients having $\mathrm{AH}$. The NO deficiency develops as a result of an oxidative stress due to inactivation of nitrogen oxide by superoxide anions and due to an exposure to an unpaired NO synthase, resulting in superoxides being produced to a greater extent than NO [25].

Thus, the intra-erythrocyte NO reserves for patients with RAH are reduced and followed by a decrease in the vasodilating NO effects at the microcirculatory level. On the other hand, there are studies that suggest that the levels of NO or NO metabolites in the erythrocytes can directly affect the ability of this cell to release the ATP $[6,7]$.

A revealed decrease in intra-erythrocyte reserves of nitrogen oxide, and a decrease in its bioavailability associated with changes in the level and composition of intracellular macroergic compounds, viscoelastic parameters of the erythrocytes are probably the pathogenetic factors for the development of resistant hypertension and targets for therapeutic effects.

The study of electrical and viscoelastic parameters of erythrocytes revealed significant differences between groups of patients with controlled and resistant AH. Red cells of patients with controlled $\mathrm{AH}$ after conversion to sucrose solution were predominantly discocytic, $22 \pm 4 \%$ of the cells acquired the form of a "deflated ball" or spherocytic. The level of non-discocytic forms among patients with RAH increased to $47 \pm 5 \%$ $(p<0.001)$, in addition, about a third of the discocytes became spiked. To ensure the integrity of the membrane and the biconcave shape of the erythrocytes, the macroergs' energy shall be of great importance [26]. Energy support for intracellular homeostasis (and, above all, ion) in erythrocytes is provided by the ATP formed during glycolysis, which is the main way of energy exchange in the erythrocytes [27]. The ATP depletion in erythrocytes leads to a number of disorders; including the interlocking the ionic pumps and changing the ion balance in the medium-cell system. This helps to reduce the ratio of surface area to erythrocytes' volume and the transformation of cells into hard-to-form spheres, the appearance of spiked processes that complicates the transport of oxygen from the erythrocytes to tissues and exacerbates hypoxia It stimulates the phenomenon of fibrogenesis, leading to internal remodeling of vessel walls [28, 29].

In the group of patients with RAH the levels of electrical conductivity, summarized rigidity, viscosity, aggregation and destruction indices have increased, and the amplitude of cell deformation, polarizability of membranes at a frequency of $10^{6} \mathrm{~Hz}$, the speed of cell movement to the electrodes, the dipole moment, and the electrical capacity of erythrocyte membranes have reliably decreased $(p<0.001-0.05)$ compared with the control group and patients with controlled $\mathrm{AH}$ (Table 2). Inverse correlations of AH resistance with the strain amplitude $(r=0.675, p=0.03)$ were obtained, as well as direct correlations with summarized parameters of rigidity $(\mathrm{r}=0.527, \mathrm{p}<0.001)$ and erythrocyte viscosity $(r=0.493, p=0.005)$. 
Table 2 Electrical and viscoelastic parameters of the erythrocytes among patients with arterial hypertension (controlled and resistant) and in the comparison group $(\mathrm{M} \pm \mathrm{m})$.

\begin{tabular}{|c|c|c|c|}
\hline $\begin{array}{l}\text { Viscoelastic and electrical } \\
\text { properties of erythrocytes }\end{array}$ & $\begin{array}{c}\text { Group I } \\
\text { of comparison } \\
n=25\end{array}$ & $\begin{array}{c}\text { Group II } \\
\text { controlled AH, } \\
\mathbf{n}=26\end{array}$ & $\begin{array}{c}\underset{\text { Group III }}{\text { resistant }} \mathbf{A H}, \\
\mathbf{n}=\mathbf{2 4}\end{array}$ \\
\hline
\end{tabular}

\begin{tabular}{|c|c|c|c|}
\hline $\begin{array}{l}\text { The amplitude of Er } \\
\text { deformation }[\mathrm{m}]\end{array}$ & $2.7 \times 10^{-6} \pm 0.6 \times 10^{-6}$ & $0.81 \times 10^{-6} \pm 0.4 \times 10^{-6} *$ & $\begin{array}{c}0.62 \times 10^{-6} \pm 0.22 \times 10^{-6} \\
* * \wedge \wedge \wedge\end{array}$ \\
\hline Summarized rigidity $[\mathrm{N} / \mathrm{m}]$ & $4.4 \times 10^{-6} \pm 0.6 \times 10^{-6}$ & $6.1 \times 10^{-6} \pm 0.7 \times 10^{-7} *$ & $\begin{array}{c}8.0 \times 10^{-6} \pm 0.5 \times 10^{-7} \\
* \wedge \wedge \wedge\end{array}$ \\
\hline $\begin{array}{l}\text { Summarized viscosity } \\
{[\mathrm{Pa} \cdot \mathrm{sec}]}\end{array}$ & $0.31 \pm 0.04$ & $0.58 \pm 0.11 *$ & $0.75 \pm 0.09^{* \wedge \wedge \wedge}$ \\
\hline $\begin{array}{l}\text { Index of Er aggregation } \\
\text { [relative un.] } \\
\end{array}$ & $0.43 \pm 0.02$ & $0.66 \pm 0.1 *$ & $0.82 \pm 0.03^{* \wedge \wedge \wedge}$ \\
\hline Index of Er destruction [\%] & $1.07 \pm 0.69$ & $5.7 \pm 0.5^{* * *}$ & $8.2 \pm 0.3 * * * \wedge \wedge \wedge$ \\
\hline $\begin{array}{l}\text { Polarization at frequency of } \\
\qquad 10^{6} \mathrm{~Hz}\left[\mathrm{~m}^{3}\right]\end{array}$ & $5.8 \times 10^{-15} \pm 0.8 \times 10^{-15}$ & $0.71 \times 10^{-15} \pm 0.6 \times 10^{-15 *}$ & $\begin{array}{c}0.52 \times 10^{-15} \pm 0.5 \times 10^{-16} \\
* * * \wedge \wedge \wedge\end{array}$ \\
\hline $\begin{array}{l}\text { Electrical conductivity } \\
{[\mathrm{Cm} / \mathrm{m}]}\end{array}$ & $2.8 \times 10^{-5} \pm 0.3 \times 10^{-5}$ & $6.1 \times 10^{-5} \pm 0.4 \times 10^{-5 * *}$ & $\begin{array}{c}7.3 \times 10^{-5} \pm 0.1 \times 10^{-5} \\
* * * \wedge \wedge \wedge\end{array}$ \\
\hline $\begin{array}{l}\text { Cellular membrane capacity } \\
{[\mathrm{F}]}\end{array}$ & $7.2 \times 10^{-14} \pm 0.2 \times 10^{-14}$ & $5.1 \times 10^{-14} \pm 0.4 \times 10^{-14 * *}$ & $\begin{array}{c}3.9 \times 10^{-14} \pm 0.2 \times 10^{-14} \\
* * * \wedge \wedge\end{array}$ \\
\hline $\begin{array}{l}\text { Velocity of Er motion, } \\
{[\mathrm{mcm} / \mathrm{sec}]}\end{array}$ & $13.9 \pm 2.5$ & $7.9 \pm 2.4$ & $5.4 \pm 1.8 * \wedge \wedge$ \\
\hline $\begin{array}{l}\text { Position of crossover } \\
\text { frequency }[\mathrm{Hz}]\end{array}$ & $4.7 \times 10^{5} \pm 0.4 \times 10^{5}$ & $6.2 \times 10^{5} \pm 0.2 \times 10^{5 * *}$ & $\begin{array}{c}7.1 \times 10^{5} \pm 0.3 \times 10^{5} \\
* * \wedge \wedge \wedge\end{array}$ \\
\hline Dipole moment $[\mathrm{Kl} \cdot \mathrm{m}]$ & $1.5 \times 10^{-21} \pm 0.4 \times 10^{-21}$ & $0.52 \times 10^{-21} \pm 0.08 \times 10^{-21} *$ & $\begin{aligned} 0.29 \times 10^{-21} & \pm 0.07 \times 10^{-21} \\
& * \wedge \wedge\end{aligned}$ \\
\hline
\end{tabular}

M stands for mean values, $m$ stands for mean error,

* - statistical significance (p) of differences from Group I $(* \mathrm{p}<0.05, * * \mathrm{p}<0.02, * * * \mathrm{p}<0.001)$;

$\wedge$ - statistical significance (p) of differences from Group II $(\wedge p<0.05, \wedge \wedge p<0.02, \wedge \wedge \wedge p<0.0001)$;

Dipole moment was calculated at electric field tension of $8.85 \cdot 10^{-12} \mathrm{~F} / \mathrm{m}$.

A deterioration of the deformability of the erythrocytes causes a development of stagnation in the microcirculatory bloodstream and, as a consequence, an occurrence of tissue hypoxia [30]. In experiments on an isolated rabbit lung, it was shown that the plasticity of the erythrocytes may affect the blood pressure value in it and the pulmonary oxygen diffusion coefficient [31]. The deformability of the erythrocytes due to an increased convection of their contents is more conducive to oxygen transport than facilitated diffusion [32].

It has been suggested that there should be a unique mechanism for controlling the resistance of pulmonary vessels, according to which the ATP release from the erythrocytes occurs in response to their mechanical deformation, causing stimulation of the synthesis of a NO vasodilator [33].

When identifying associations between the electrical and viscoelastic parameters of erythrocytes and hemoglobin complexes, the most significant correlations were found in the group of patients with resistant $\mathrm{AH}$ (Table 3).

It has been found that the closest and most reliable correlations was established between the intensity of peaks reflecting the levels of hemoglobin complexes with nitrogen oxide, and the amplitude of deformation and summarized indicators of viscosity and rigidity. Moreover, the latter association was the strongest one that is probably possible due to the fact that the value of this indicator depends on both the properties of the erythrocyte membrane and its internal content hemoglobin. The summarized viscosity index is determined by the degree of friction between different cell layers, i.e. it depends on the properties of the entire cell volume [19].

The correlations revealed are obviously not random. It was shown that erythrocytes react with NO synthesized and delivered from the endothelial cells [34]. At the same time, it was found that the erythrocytes have their own NO-synthase for the 
Table 3 Correlations between the levels of the coherent Raman scattering peaks of hemoglobin complexes and the values of electrical and viscoelastic parameters of erythrocyte among patients with resistant arterial hypertension.

\begin{tabular}{|c|c|c|c|c|c|c|c|}
\hline $\begin{array}{c}\text { The } \\
\text { position } \\
\text { of the } \\
\text { peak } \\
{\left[\mathrm{cm}^{-1}\right]}\end{array}$ & $\begin{array}{c}\text { The } \\
\text { amplitude of } \\
\text { Er } \\
\text { deformation } \\
{[\mathrm{m}]} \\
\end{array}$ & $\begin{array}{c}\text { Summariz } \\
\text { ed rigidity } \\
{[\mathbf{N} / \mathbf{m}]}\end{array}$ & $\begin{array}{c}\text { Summarize } \\
\text { d viscosity } \\
{[\mathrm{Pa} \times \text { sec }]}\end{array}$ & $\begin{array}{c}\text { Polarization } \\
\text { at frequency } \\
\text { of } 10^{6} \mathrm{~Hz} \\
{\left[\mathrm{~m}^{3}\right]}\end{array}$ & $\begin{array}{c}\text { Index of Er } \\
\text { destruction } \\
{[\%]}\end{array}$ & $\begin{array}{l}\text { Electrical } \\
\text { conductivi } \\
\text { ty }[\mathrm{Cm} / \mathrm{m}]\end{array}$ & $\begin{array}{c}\text { Dipole } \\
\text { moment } \\
\text { [Kl'm] }\end{array}$ \\
\hline 1325 (I) & $\begin{array}{l}0.312 \\
(0.03)\end{array}$ & $\begin{array}{l}-0.243 \\
(0.001)\end{array}$ & $\begin{array}{l}-0.215 \\
(0.05)\end{array}$ & $\begin{array}{c}0.181 \\
(0.014)\end{array}$ & $\begin{array}{l}-0.217 \\
(0.03)\end{array}$ & $\begin{array}{l}-0.169 \\
(0.002)\end{array}$ & $\begin{array}{c}0.232 \\
(0.002)\end{array}$ \\
\hline 1350 (II) & $\begin{array}{c}0.401 \\
(0.001)\end{array}$ & $\begin{array}{l}-0.415 \\
(0.008)\end{array}$ & $\begin{array}{l}-0.397 \\
(0.043)\end{array}$ & $\begin{array}{c}0.298 \\
(0.003)\end{array}$ & $\begin{array}{l}-0.413 \\
(0.009)\end{array}$ & $\begin{array}{l}-0.314 \\
(0.033)\end{array}$ & $\begin{array}{l}0.362 \\
(0.05)\end{array}$ \\
\hline 1550 (III) & $\begin{array}{l}0.284 \\
(0.04)\end{array}$ & $\begin{array}{l}-0.118 \\
(0.008)\end{array}$ & $\begin{array}{l}-0.239 \\
(0.001)\end{array}$ & $\begin{array}{c}0.211 \\
(0.023)\end{array}$ & $\begin{array}{l}-0.262 \\
(0.017)\end{array}$ & $\begin{array}{l}-0.218 \\
(0.006)\end{array}$ & $\begin{array}{c}0.301 \\
(0.009)\end{array}$ \\
\hline 1580 (IV) & $\begin{array}{c}0.378 \\
(0.001)\end{array}$ & $\begin{array}{l}-0.412 \\
(0.007)\end{array}$ & $\begin{array}{l}-0.349 \\
(0.004)\end{array}$ & $\begin{array}{l}0.409 \\
(0.01)\end{array}$ & $\begin{array}{l}-0.362 \\
(0.04)\end{array}$ & $\begin{array}{l}-0.422 \\
(0.001)\end{array}$ & $\begin{array}{l}0.437 \\
(0.05)\end{array}$ \\
\hline $1610(\mathrm{~V})$ & $\begin{array}{l}0.435 \\
(0.01)\end{array}$ & $\begin{array}{l}-0.463 \\
(0.001)\end{array}$ & $\begin{array}{l}-0.417 \\
(0.003)\end{array}$ & $\begin{array}{c}0.354 \\
(0.016)\end{array}$ & $\begin{array}{l}-0.330 \\
(0.056)\end{array}$ & $\begin{array}{l}-0.397 \\
(0.04)\end{array}$ & $\begin{array}{c}0.428 \\
(0.033)\end{array}$ \\
\hline $1680(\mathrm{VI})$ & $\begin{array}{c}0.571 \\
(0.0001)\end{array}$ & $\begin{array}{c}-0.610 \\
(0.0001)\end{array}$ & $\begin{array}{c}-0.466 \\
(0.0001)\end{array}$ & $\begin{array}{c}0.411 \\
(0.004)\end{array}$ & $\begin{array}{l}-0.367 \\
(0.05)\end{array}$ & $\begin{array}{l}-0.429 \\
(0.038)\end{array}$ & $\begin{array}{c}0.503 \\
(0.008)\end{array}$ \\
\hline $\mathrm{I}_{1680} / \mathrm{I}_{1580}$ & $\begin{array}{c}0.537 \\
(0.007)\end{array}$ & $\begin{array}{l}-0.560 \\
(0.004)\end{array}$ & $\begin{array}{l}-0.447 \\
(0.002)\end{array}$ & $\begin{array}{c}0.463 \\
(0.006)\end{array}$ & $\begin{array}{l}-0.419 \\
(0.003)\end{array}$ & $\begin{array}{l}-0.407 \\
(0.005)\end{array}$ & $\begin{array}{l}0.471 \\
(0.02)\end{array}$ \\
\hline
\end{tabular}

The numbers in brackets in the first column correspond to the main signals of hemoglobin forms and its complexes as indicated in Fig. 1.

The confidence level of the association is indicated in parentheses.

Table 4 Results of the combined assessment of the Raman signals for aqueous solutions of hemoglobin, electrical, viscoelastic parameters of the erythrocytes among patients with $\mathrm{AH}$ for detecting resistant and controlled forms of the disease in comparison with the data of combined clinical and instrumental research methods.

Results of a combined study of Raman spectra for aqueous solutions of hemoglobin, electrical, viscoelastic parameters of erythrocytes

The group with controlled $\mathrm{AH}$ $\mathrm{n}=24$ cases

The group with resistant $\mathrm{AH}$ $\mathrm{n}=26$ cases
Results of clinical and instrumental research methods

The group with controlled $\mathrm{AH} \quad$ The group with resistant $\mathrm{AH}$ $\mathrm{n}=26$ cases

True positive

The group with controlled AH $n=22$

False negative

The group with controlled AH

$$
\mathrm{n}=4
$$

$$
\mathrm{n}=24 \text { cases }
$$

\section{False positive}

The group with resistant $\mathrm{AH}$ $\mathrm{n}=2$

\section{True negative}

The group with resistant $\mathrm{AH}$ $\mathrm{n}=22$

Below are calculations of the main characteristics of the method according to Greenhalgh T. [24].

Sensitivity

Specificity

Prognostic value

of positive method results

Prognostic value

of negative method results

Accuracy index

$$
\begin{aligned}
& 22 /(22+4) \times 100 \%=84.6 \% \\
& 22 /(22+2) \times 100 \%=91.7 \% \\
& 22 /(22+2) \times 100 \%=91.7 \% \\
& 22 /(22+4) \times 100 \%=84.6 \% \\
& (22+22) /(22+2+22+4) \times 100 \%=88 \%
\end{aligned}
$$

synthesis of their own NO but this process is implemented with a sufficient degree of deformability of the erythrocytes [35]. Based on these data, the plastic erythrocytes are a powerful endogenous source of NO. Therefore, the erythrocytes with reduced deformability and low reserves of intra-erythrocyte NO do not provide sufficient levels of extracellular nitrogen oxide with subsequent vasodilation. Therefore, peripheral resistance will increase, leading to an increase in BP, that is a pathogenetic basis for the development of resistant $\mathrm{AH}$.

It should be noted that the levels of deoxyhemoglobin, oxyhemoglobin, and hemoglobin complexes with NO were significant for the indicator of cell polarizability that reflects the degree of their viability. Reduced intra-erythrocyte reserves of 
hemoglobin complexes affect the resistance of the erythrocytes as a likely manifestation of decompensation in RAH, determining a decline of this resistance. This results in excessive hemolysis of the erythrocytes that probably explains the correlation of the destruction index with the peak intensities of hemoglobin compounds. On the other hand, the changed levels of hemoglobin forms and its complexes may affect the mechanisms of their transformations related to the state of cell membranes. Indirectly, this is evidenced by correlations of erythrocyte compounds with the level of electrical conductivity of cell membranes and the value of the dipole moment reflecting the electric charge of the cell $[18,19]$. It should be noted that the ratio of Raman signals $I_{1680} / I_{1580}$, reflecting the ability of hemoglobin to give oxygen, was directly related to the ability of the erythrocytes to be deformed. At the same time, this ratio was correlated with parameters that reflect the charge of cells - the dipole moment, the degree of cell viability - polarizability and the index of destruction. The resulting associations are obviously one of the factors that lead to an increase in tissue hypoxia for patients with RAH [2].

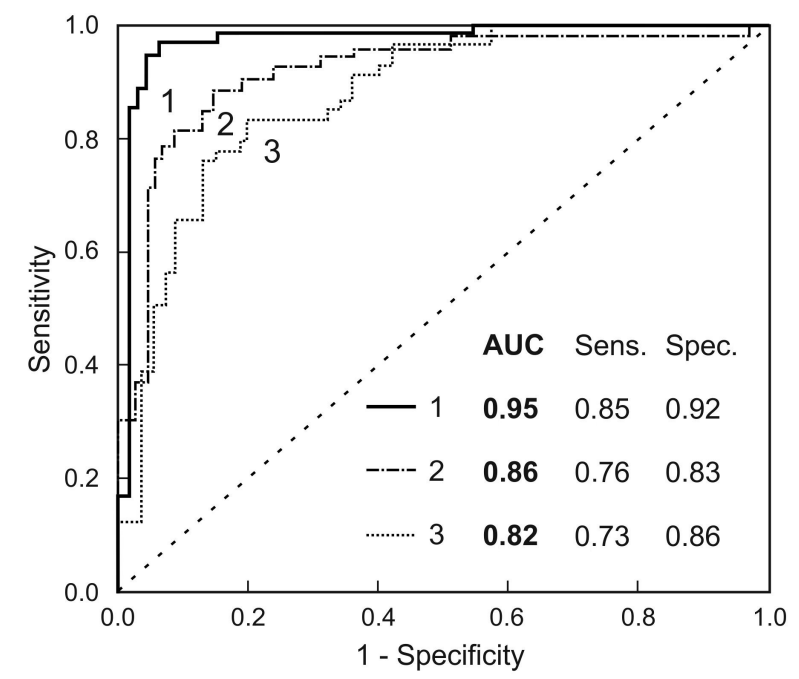

Fig. 3 ROC-curves of signal intensities of Raman spectra of aqueous solutions of hemoglobin, electrical and viscoelastic parameters of erythrocytes for differential diagnosis of resistant and controlled AH. 1 a ROC-curve when using Raman spectroscopy and dielectrophoresis combined; 2 - a ROC-curve for Raman spectroscopy; 3 - a ROC-curve for erythrocyte dielectrophoresis.

To evaluate the significance of the peak intensities of the Raman spectra for hemoglobin solutions, electrical and viscoelastic parameters of the erythrocytes in terms of differential diagnosis of resistant and controlled hypertension, the ROC analysis has been used by means of the construction of receiving characteristic curves (ROC curves), the results of which are presented in Fig. 3. During the analysis, the first model has been formed from the peak intensities of the coherent Raman scattering spectrum of hemoglobin, the second one from a set of electrical and viscoelastic parameters of the erythrocytes, the third one is a combination of Raman spectroscopy data and of dielectrophoresis. It was turned out that the use of two methods simultaneously increases diagnostic accuracy $(88 \%)$, sensitivity $(84.6 \%)$, and specificity $(91.7 \%)$ in distinguishing resistant from controlled hypertension, as opposed to methods used separately.

Results of the combined assessment of the Raman peaks for aqueous solutions of hemoglobin, electrical, viscoelastic parameters of the erythrocytes among patients with $\mathrm{AH}$ for detecting resistant and controlled forms of the disease in comparison with the data of combined clinical and instrumental research methods are presented in Table 4 [36]. Especially, the prospects are important for determining truly positive results for RAH (according to the prognostic value of the negative result) due to the need for a complex of social, therapeutic, and adaptive measures.

\section{Summary}

Thus, the study of changes in the content of hemoglobin complexes by the Raman spectroscopy, electrical and viscoelastic parameters of the erythrocytes among patients with $\mathrm{AH}$ allowed us to draw the following conclusions:

- We have determined a significant decrease in the level of hemoglobin-ligand complexes, Hb-NO (II) complexes in patients with RAH compared to those among patients with controlled $\mathrm{AH}$ and among healthy patients $(p<0.001-0.05)$, that probably reflects the reduced reserves of erythrocytic NO and a decrease in $\mathrm{O}_{2}$ release.

- Among patients with resistant $\mathrm{AH}$, the levels of electrical conductivity, summarized indicators of rigidity, viscosity, the indices of aggregation, and destruction are significantly higher, and the amplitude of cell deformation, polarizability of membranes at a frequency of $10^{6} \mathrm{~Hz}$, the speed of cell movement to the electrodes, the dipole moment, and the electrical capacity of erythrocyte membranes are lower than those in the control group and patients with controlled $\mathrm{AH}$ $(\mathrm{p}<0.0001-0.05)$;

- We have found correlation between the intensities of the most important signals of Raman spectra of hemoglobin $(1325,1350,1550,1580,1660$, $\left.1668 \mathrm{~cm}^{-1}, \mathrm{I}_{1680} / \mathrm{I}_{1580}\right)$ and electric and viscoelastic parameters of erythrocytes (amplitude of deformation of erythrocytes, summarized indicators of viscosity and rigidity, the magnitude of the dipole moment, polarizability at the frequency $10^{6} \mathrm{~Hz}$, electrical conductivity, index of destruction), the intensity of which was the biggest one for resistant $\mathrm{AH}$;

- The combined use of two methods (Raman spectroscopy of hemoglobin and electrical and viscoelastic indicators of the erythrocytes) allowed to increase the diagnostic accuracy in detecting RAH up to $88 \%$, sensitivity up to $84.6 \%$, specificity up to $91.7 \%$ compared to the data of the combined clinical and 
instrumental methods of research, which exceeds the capabilities of the methods separately.

Thus, the combined use of the above methods in clinical practice will reduce the material, time, and labor costs for the diagnosis and treatment of the RAH and its consequences, and will make it possible to identify new targets for therapeutic effects.

\section{Disclosures}

All authors declare that there is no conflict of interests in this paper.

\section{Acknowledgence}

This work was done within the publicly funded topic in State Assignment No. AAAA-A17-117112850280-2.

\section{References}

1. S. A. Boitsov, R. G. Oganov, "Experience in the prevention of cardiovascular diseases in the country," Therapeutic archive 84(9), 4-10 (2012) [in Russian].

2. A. N. Britov, M. M. Bystrova, "Refractory hypertension - modern approaches to diagnostics and treatment," Rational pharmacotherapy in cardiology 6(2), 206-211 (2010) [in Russian].

3. V. A. Dmitriev, E. V. Oschepkova, V. N. Titov, A. N. Rogoza, T. V. Balakhonova, O. A. Pogorelova, V. P. Masenko, and D. M. Ataullakhanova, "C-reactive protein and interleikin-6 in damage of target-organs of patients at early stages of hypertension," Kardiologicheskii vestnik 2(2), 45-49 (2007) [in Russian].

4. E. V. Oschepkova, V. A. Dmitriev, and V. N. Titov, "Non-specific inflammation rates in hypertensive patients," Therapeutic archive 12, 62-67 (2007) [in Russian].

5. S. Spina, C. Lei, R. Pinciroli, and L. Berra, "Hemolysis and kidney injury in cardiac surgery: The protective role of nitric oxide therapy," Seminars in Nephrology 39(5), 484-495 (2019).

6. J. T. Alexander, A. M. El-Ali, J. L. Newman, S. Karatela, B. L. Predmore, D. J. Lefer, R. L. Sutliff, and J. D. Roback, "Red blood cells stored for increasing periods produce progressive impairments in nitric oxide-mediated vasodilation," Transfusion 53, 2619-2628 (2013).

7. J. Carroll, M. Raththagala, W. Subasinghe, S. Baguzis, T. D. A. Oblak, P. Root, and D. Spence, “An altered oxidant defense system in red blood cells affects their ability to release nitric oxidestimulating ATP," Molecular BioSystems 2(6-7), 305-311 (2006).

8. R. S. Sprague, A. H. Stephenson, E. A. Bowles, M. S. Stumpf, and A. J. Lonigro, "Reduced expression of Gi in erythrocytes of humans with type 2 diabetes is associated with impairment of both cAMP generation and ATP release," Diabetes 55(12), 3588-3593 (2006).

9. C. C. Helms, M. T. Gladwin, and D. B. Kim-Shapiro, "Erythrocytes and Vascular Function: Oxygen and Nitric Oxide," Frontiers in Physiology 9, 1-125 (2018).

10. "Working Group for the Treatment of Arterial Hypertension of the European Society of Hypertension. Recommendations for the treatment of arterial hypertension. ESH/ESC 2013," Russian cardiologic journal 1(105), 7-94 (2014) [in Russian].

11. S. T. Halpin, D. M. Spence, "Direct plate-reader measurement of nitric oxide released from hypoxic erythrocytes flowing through a microfluidic device," Analytical Chemistry 82, 7492-7497 (2010).

12. M. V. Kruchinina, A. A. Gromov, Ya. Sh. Shvartz, A. V. Rabko, V. A. Baum, V. M. Generalov, V. N. Kruchinin, S. V. Rykhlitskii, and V. A. Volodin, "Resistant arterial hypertension: some aspects of pathogenesis," Atherosclerosis 11(3), 5-14 (2015) [in Russian].

13. Ya. Sh. Shvartz, M. V. Kruchinina, M. M. Timofeeva, M. I. Rudina, O. M. Dolganova, A. A. Gromov, V. A. Baum, and A. V. Rabko, "Determining the ability of erythrocyte to generate nitric oxide in patients with cardiovascular diseases," International Journal of Applied and Fundamental Research 4(2), 386-391 (2016) [in Russian].

14. M. V. Kruchinina, Ya. Sh. Shvartz, A. A. Gromov, V. N. Kruchinin, V. A. Volodin, and S. V. Rykhlitskii, "Raman-spectroscopy of hemoglobine in diagnostics of resistant arterial hypertension," Atherosclerosis 12(4), 2229 (2016) [in Russian].

15. M. V. Kruchinina, A. A. Gromov, A. V. Rabko, V. A. Baum, V. M. Generalov, V. N. Kruchinin, S. V. Rykhlitskii, and V. A. Volodin, "Are there any differences in the optical parameters of blood associated with the degree of arterial hypertension?" Atherosclerosis 10(1), 22-31 (2014) [in Russian].

16. S. Uskokovic-Markovic, M. Jelikic-Stankov, I. Holclajtner-Antunovic, and P. Durdevic, "Raman spectroscopy as a new biochemical diagnostic tool," Journal of Medical Biochemistry 32(2), 96-103 (2013).

17. G. W. Auner, S. K. Koya, C. Huang, B. Broadbent, M. Trexler, Z. Auner, A. Elias, K. C. Mehne, and M. A. Brusatori, "Applications of Raman spectroscopy in cancer diagnosis," Cancer and Metastasis Reviews 37(4), 691717 (2018).

18. V. M. Generalov, M. V. Kruchinina, A. G. Durymanov, A. A. Medvedev, A. S. Safatov, A. N. Sergeev, G. A. Buryak, S. A. Kurilovich, and A. A. Gromov, Dielectrophoresis in the diagnosis of infectious and non-infectious 
diseases, V. M. Generalov, M. V. Kruchinina (eds.), CERIS, Novosibirsk (2011) [in Russian]. ISBN 978-5-70070256-4.

19. V. M. Generalov, M. V. Kruchinina, A. A. Gromov, and G. V. Shuvalov, Dielectrophoresis in biology and medicine, Publishing office of NGTU, Novosibirsk (2017) [in Russian]. ISBN 978-5-7782-3485-7.

20. M. V. Kruchinina, S. A. Kurilovich, M. I. Voevoda, A. A. Gromov, V. M. Generalov, A. S. Safatov, G. A. Buryak, and K. V. Generalov, "Associations of erythrocyte parameters with viral loadin patients with chronic viral hepatitis C," Vestnik NGU 13(2), 5-17 (2015) [in Russian].

21. M. V. Kruchinina, S. A. Kurilovich, A. A. Gromov, V. M. Generalov, and V. N. Kruchinin, "Peculiarities of erythrocytic parameters in patients with nonalcoholic steatohepatitis," Journal of Analytical Sciences, Methods and Instrumentation 6(1), 6-14 (2016).

22. M. V. Kruchinina, A. V. Starikov, A. A. Gromov, and V. M. Generalov, "Interaction of electrical and viscoelastic parameters with biochemistry parameters in patients with various stages of colorectal cancer," Therapy 3(7), 40-47 (2016) [in Russian].

23. M. V. Kruchinina, A. A. Gromov, M. V. Parulikova, M. G. Golovin, V. A. Baum, V. M. Generalov, K. V. Generalov, and V. N. Kruchinin, "Diagnostic possibilities for rheological disorders in patients with type 2 diabetes," Modern problems of science and education 5 (2017).

24. O. V. Rodnenkov, O. G. Luneva, N. A. Ulyanova, G. V. Maksimov, A. B.Rubin, S. N. Orlov, and E. I. Chazov, "Erythrocyte membrane fluidity and haemoglobin haemoporphyrin conformation: features revealed in patients with heart failure," Pathophysiology 11(4), 209-213 (2005).

25. I. E. Chazova, N. M. Danilov, and A. Yu. Litvin, Refractory arterial hypertension: Monography, Moscow, Atmosphere (2014) [in Russian].

26. A. S. Said, S. C. Rogers, and A. Doctor, "Physiologic Impact of Circulating RBC Microparticles upon BloodVascular Interactions," Frontiers in Physiology 8, 1120 (2017).

27. G. J. Bosman, "The involvement of erythrocyte metabolism in organismal homeostasis in health and disease," PROTEOMICS - Clinical Applications 10(8) 774-777 (2016).

28. E. B. Menshikova, V. Z. Lankin, N. K. Zenkov, I. A. Bondar, N. F. Krugovyh, and V. A. Trufakin, Oxidative stress. Prooxidants and antioxidants, Moscow, Slovo (2006) [in Russian].

29. V. V. Novitskij, N. V. Ryazantseva, and E. A. Stepovaya, The physiology and pathophysiology of red blood cells, Publishing office of TGU, Tomsk (2004) [in Russian].

30. M. Becatti, R. Marcucci, A. M. Gori, L. Mannini, E. Grifoni, A. A. Liotta, A. Sodi, R. Tartaro, N. Taddei, S. Rizzo, D. Prisco, R. Abbate, and C. Fiorillo, "Erythrocyte oxidative stress is associated with cell deformability in patients with retinal vein occlusion," Journal of Thrombosis and Haemostasis 14(11), 2287-2297 (2016).

31. A. I. Berezniakova, O. D. Zhemela, "Deformability of the erythrocytes membrane in rats of different age in hypoxia," Fiziolohichny̌̌ zhurnal 59(3), 72-77 (2013).

32. M. Tarasev, M. Muchnik, L. Light, K. Alfano, and S. Chakraborty, "Individual variability in response to a single sickling event for normal, sickle cell, and sickle trait erythrocytes," Translational Research 181, 96-107 (2017).

33. Y. Zhao, X. Wang, M. Noviana, and M. Hou, "Nitric oxide in red blood cell adaptation to hypoxia," Acta Biochimica et Biophysica Sinica 50(7), 621-634 (2018).

34. M. Grau, A. Lauten, S. Hoeppener, B. Goebel, J. Brenig, C. Jung, W. Bloch, and F. Suhr, "Regulation of red blood cell deformability is independent of red blood cell-nitric oxide synthase under hypoxia," Clinical Hemorheology and Microcirculation 63(3), 199-215 (2016).

35. O. V. Kosmachevskaya, A. F. Topunov, "Alternate and Additional Functions of Erythrocyte Hemoglobin," Biochemistry (Moscow) 83(12) 1575-1593 (2018).

36. T. Greenhalgh, How to read a paper: the basics of evidence-based medicine, Fifth edition, BMJ Books (2014). 